\title{
Invasiveness of Salmonella serotypes Typhimurium, Choleraesuis and Dublin for rabbit terminal ileum in vitro
}

\author{
ALEX J. BOLTON, GILLIAN D. MARTIN, MICHAEL P. OSBORNE*, TIM S. WALLIS $\dagger$ and JOHN \\ STEPHEN
}

Microbial Molecular Genetics and Cell Biology Group, School of Biological Sciences and *Department of Physiology, Medical School, University of Birmingham, Edgbaston, Birmingham B15 2TT and †Institute for Animal Health, Compton, Newbury, Berkshire RG20 7NN

\begin{abstract}
Ten recent clinical isolates of Salmonella serotype Typhimurium from man that were tested for their invasiveness in rabbit ileal explants in vitro, were compared with Typhimurium strain TML, a well-characterised invasive strain isolated from a case of human gastro-enteritis. Nine of the 10 strains showed invasiveness that was comparable to that of strain TML. One isolate (GM3) was apparently substantially less invasive; electron microscopy showed this strain to be histotoxic - the probable reason for its reduced recovery from ileal mucosa and thus apparent 'low' invasiveness. Salmonella serotype Choleraesuis strain A50, isolated from a case of systemic salmonellosis in pigs, and serotype Dublin strain 3246, isolated from a case of systemic salmonellosis in calves, were also examined. Dublin strain 3246 , when grown at $37^{\circ} \mathrm{C}$ and used immediately in the invasion assay, damaged the mucosa in a manner similar to that of Typhimurium strain GM3, whereas Dublin strain 3246 grown at $37^{\circ} \mathrm{C}$ and stored overnight at $4^{\circ} \mathrm{C}$ did not. This was reflected in an apparently lower invasiveness of freshly grown organisms compared with that of organisms stored at $4^{\circ} \mathrm{C}$. In contrast, the histotoxicity of Typhimurium strain GM3 was not affected by storage at $4^{\circ} \mathrm{C}$. When stored at $4^{\circ} \mathrm{C}$, the levels of invasiveness of Choleraesuis strain A50 and Dublin strain 3246 were not significantly different from each other or from Typhimurium strain TML.
\end{abstract}

\section{Introduction}

As virulence in Salmonella is multifactorial, hostdependent and, in naturally occurring settings, often host-restricted, the choice of organism-host combination for experimental study and the precise definition of the question(s) to be addressed are of crucial importance. Therefore, it follows that generalised extrapolation from findings in studies involving one strain of one serotype of Salmonella and one host - be that whole animal, organ culture or cells in culture must be made with great caution. Too few studies of any one narrowly defined aspect of the complex Salmonella-host interaction have been performed with a range of non-manipulated wild-type strains of a given serotype. This report presents an extension of previous work on the invasiveness of Salmonella serotype Typhimurium strains of human origin for rabbit

Received 1 Sept. 1998; revised version accepted 8 Dec. 1998.

Corresponding author: Dr. J. Stephen. intestinal tissue. The rabbit is regarded as a good laboratory animal model for experimental studies of human gastro-enteritis [1]. A further aim was to examine the invasive characteristics of serotypes Choleraesuis and Dublin in this in-vitro system as part of a larger study designed to elucidate the basis of the, as yet poorly understood, phenomenon of host restriction exhibited by certain serotypes of Salmonella under natural conditions. The particular association of some serotypes of Salmonella with specific hosts might be determined by either a predilection of the organism for certain hosts or resistance of insusceptible hosts to certain serotypes.

This laboratory has developed an organ-culture technique in which explants of rabbit terminal ileum have been used to study the invasiveness of Salmonella serotype Typhimurium [2,3] and Enterobacter cloacae [4] for gut enterocytes in situ. There are two reasons why the system allows primary invasion of enterocytes by bacteria to be studied. First, the structure of rabbit small intestine is such that Peyer's patches occur as 
small discrete patches which are easily avoided in the selective explantation of absorptive epithelia. Second, as experiments are usually restricted to $1-2 \mathrm{~h}(3 \mathrm{~h}$ maximum), only the initial events, i.e., interaction between the pathogen and enterocytes in situ and generally with only limited subepithelial invasion, are observed. Seven Typhimurium strains of defined virulence were assessed originally in the intestinal invasion assay: three virulent strains (TML, W118 and Wake from human clinical cases) that caused fluid secretion in rabbit ileal loops [2] proved invasive; and four strains (LT7, SL1027, M206 and Thax-1), avirulent in terms of their failure to cause disease in monkeys or fluid secretion in rabbit loops [2], proved to be non-invasive. These studies have now been extended to include another 10 contemporary Typhimurium strains of human clinical origin. The first objective of the work was to determine if the correlation between the ability to invade gut epithelia and virulence, as suggested in a previous study [2], was true for a larger number of Typhimurium strains. Such a result would have considerable significance in developing an accurate concept of the pathophysiological basis of disease caused by Typhimurium.

Second, Salmonella serotype Choleraesuis strain A50 and serotype Dublin strain 3246 were also selected for study because of their abilities to cause experimentally induced systemic salmonellosis in pigs and calves, respectively (unpublished data). If host restriction is determined by the efficiency with which primary invasion of 'homologous' intestinal mucosae takes place, then it may be argued that Choleraesuis and Dublin strains would not show the same degree of invasiveness for rabbit ileal enterocytes as the nonrestricted serotype Typhimurium.

\section{Materials and methods}

\section{Bacterial strains}

Ten Typhimurium strains (designated GM1-10), randomly selected from recent clinical cases, were obtained from Dr B. Rowe (Laboratory of Enteric Pathogens, Central Public Health Laboratory, 61 Colindale Avenue, London). They were transported and kept on Dorset's egg medium slopes at room temperature. Also, Typhimurium strains TML and LT7 [1] were used. Salmonella serotype Choleraesuis var. kunzendorf strain A50 was isolated from a systemic case of salmonellosis in pigs in the UK and serotype Dublin strain 3246 from a systemic case of salmonellosis in calves in the UK (T. S. Wallis, unpublished data).

\section{Storage and culture conditions}

Strains were streaked on to plates of MacConkey agar (Becton Dickinson, Microbiology Systems, Oxford) from original stocks. Three colonies were used to inoculate Mueller-Hinton broth $(1 \mathrm{ml})$ which was incubated for $3 \mathrm{~h}$ at $37^{\circ} \mathrm{C}$. After incubation, an equal volume of sterile glycerol was added to each culture. For long-term storage, strains were held at $-70^{\circ} \mathrm{C}$ and for short-term storage at $-20^{\circ} \mathrm{C}$. Stocks stored at $-20^{\circ} \mathrm{C}$ were used for up to a maximum of five times.

\section{Media}

BBL MacConkey agar without crystal violet or salt (Becton Dickinson), Hartley Digest Broth (HDB; Oxoid) and Mueller-Hinton Broth (Oxoid) were prepared according to the manufacturers' instructions. Media were sterilised by autoclaving $\left(15 \mathrm{psi}, 121^{\circ} \mathrm{C}\right.$, for $15 \mathrm{~min}$ ).

\section{Animals}

Intestinal tissue was obtained from New Zealand White rabbits weighing $2.5-3.0 \mathrm{~kg}$ (Froxfield, Hampshire). They were observed for any manifestations of gastrointestinal disturbance and only symptom-free animals were used.

\section{Apparatus for organ culture}

A 12-chamber version of that described previously [2] was used. Pieces of intestinal tissue were stripped of serosal and muscular layers and mounted in the apparatus such that, when clamped together, the mucosae faced one side of the chamber and serosae the other. In this asymmetrical system only the mucosal side of the explant was exposed to bacteria. Media within chambers were gassed continually with a mixture of $\mathrm{O}_{2} 95 \%$ and $\mathrm{CO}_{2} 5 \%$.

\section{Media and solutions for organ culture}

Serosal solution (WHO rehydration formulation) contained $60 \mathrm{mM} \mathrm{NaCl}, 30 \mathrm{mM} \mathrm{NaHCO}, 20 \mathrm{mM} \mathrm{KCl}$, and $111 \mathrm{mM}$ glucose. Solution $\mathrm{C}$ was serosal solution except that $60 \mathrm{mM} \mathrm{NaCl}$ was replaced by $60 \mathrm{mM}$ choline chloride, and $30 \mathrm{mM} \mathrm{NaHCO}$ by $30 \mathrm{~mm}$ choline bicarbonate (choline compounds were obtained from Sigma). Tissue culture medium (TCM) was Minimal Essential Medium (LIFE, Paisley) containing Earle's salts but without glutamine; glutamine was added at a final concentration of $2.0 \mathrm{~mm}$ and Fetal Calf Serum (Northumbria Biologicals, Cramlington) to a final concentration of $10 \% \mathrm{v} / \mathrm{v}$. Mucosal solution was solution $\mathrm{C}$ with $\mathrm{TCM}$ at $10 \% \mathrm{v} / \mathrm{v}$.

\section{Rabbit ileal invasion assays (RIIAs)}

Bacteria were grown without shaking at $37^{\circ} \mathrm{C}$ overnight in $\mathrm{HDB}$. The culture was centrifuged $(4500 \mathrm{~g}, 10 \mathrm{~min}$ at room temperature) and the pellet was resuspended in fresh $\mathrm{HDB}(10 \mathrm{ml})$. One $\mathrm{ml}$ of this suspension was used to inoculate $\mathrm{HDB}(90 \mathrm{ml})$ which was incubated statically at $37^{\circ} \mathrm{C}$ for a further $3 \mathrm{~h}$ to exponential phase. Bacteria were harvested by centrifugation and resus- 
pended in mucosal solution $\left(c .10^{8} \mathrm{cfu} / \mathrm{ml}\right)$. It should be noted that for some experiments, designed principally for electron microscopy, $10^{9} \mathrm{cfu} / \mathrm{ml}$ was used as inoculum, because location of bacteria associated with mucosa was difficult with smaller inocula. Bacterial suspensions were either used immediately or stored overnight on ice held at $4^{\circ} \mathrm{C}$. The mucosal surface of rabbit ileal tissue $\left(50 \mathrm{~mm}^{2}\right.$ in each chamber) was challenged with bacterial suspension $(3 \mathrm{ml})$. Serosal surfaces were bathed in serosal solution $(3 \mathrm{ml})$. The organ culture apparatus was then incubated for $2 \mathrm{~h}$ at $37^{\circ} \mathrm{C}$. Culture medium was removed from each 'mucosal' chamber and residual extracellular bacteria were killed by addition of fresh medium containing gentamicin $100 \mu \mathrm{g} / \mathrm{ml}$ for $1 \mathrm{~h}$ at $37^{\circ} \mathrm{C}$. Tissue was removed from the organ-culture apparatus, washed in isotonic saline and a piece of mucosa (12-mm diameter) from each chamber was cut out with a cork borer. Tissue was homogenised on ice in Triton X-100 $1 \% \mathrm{v} / \mathrm{v}$ in phosphate-buffered saline $(3 \mathrm{ml})$ in a Sorvall Omnimixer (Sorvall, Newtown, CT, USA) at maximum speed for $30 \mathrm{~s}$ to release intracellular bacteria. Invasiveness was expressed as the percentage of the initial inoculum recovered from the tissue. Because of between-animal variations, data were normalised to the invasiveness of Typhimurium strain TML to allow inter-experimental comparisons, as described previously $[2,3]$.

\section{Scanning electron microscopy}

Gut was challenged with various strains as described for RIIAs. The normal procedure was carried out, except that tissues were not homogenised for quantitative analysis, but were taken for electron microscopy. Gut tissue was fixed in glutaraldehyde $2.5 \% \mathrm{v} / \mathrm{v}$ in phosphate buffer ( $\mathrm{pH} 7.2$ ) for $24 \mathrm{~h}$. Tissues were then dehydrated serially through a series of aqueous solutions of increasing acetone concentrations $-50 \%$, $70 \%, 90 \%, 95 \%, 100 \%$ - and $100 \%$ acetone (dried over $\mathrm{CuSO}_{4}$ ), with two 15-min washes for each acetone concentration. Tissue was dried in a critical point drier with liquid $\mathrm{CO}_{2}$ (Polaron E3000 series II). Pieces of tissue were mounted on copper stubs with Araldite Rapid (Ciba-Geigy) and sputter-coated with platinum in a low-voltage sputter coater (EMSCOPE SC500) operated at $100-150 \mathrm{~V}$ with $10-20 \mathrm{~mA}$ current.

\section{Transmission electron microscopy}

Tissues were taken as described for scanning electron microscopy and fixed in glutaraldehyde $2.5 \% \mathrm{v} / \mathrm{v}$ for $1 \mathrm{~h}$, then post-fixed in $\mathrm{OsO}_{4} 1 \%$ for $1 \mathrm{~h}$; glutaraldehyde and $\mathrm{OsO}_{4}$ solutions were prepared in phosphate buffer $(\mathrm{pH} 7.2)$ containing $350 \mathrm{mM}$ sucrose. Tissues were then dehydrated serially through a series of aqueous solutions of increasing ethanol concentrations $-70 \%$, $90 \%, 100 \%$ and $100 \%$ ethanol (dried over $\mathrm{CuSO}_{4}$ ) treated with propylene oxide and embedded in EponAraldite [1]. Sections (c. $2.5 \mu \mathrm{m}$ thick) were stained with toluidine blue $1 \%$ and observed by light microscopy. Ultra-thin sections (c. 90-nm thick) were cut, mounted on Formvar-coated copper grids and stained with methanolic uranyl acetate and Reynold's lead citrate and examined in a JEOL $100 \mathrm{CX}$ II electron microscope at an accelerating voltage of $60 \mathrm{kV}$.

\section{Results \\ Preliminary experiments}

In applying the general principles of RIIA to the study of invasiveness of any new organism, it is important to establish the viability of the organism in mucosal solution and its sensitivity to gentamicin. Viabilities of Choleraesuis strain A50, Dublin strain 3246 and 10 Typhimurium strains in mucosal solution were similar and did not decline over $3 \mathrm{~h}$. All strains were sensitive to gentamicin.

\section{Assessment of invasiveness}

Inoculum sizes were always adjusted to give similar numbers of bacteria, because factors such as bacteriaenterocyte saturation, or cell damage resulting in loss of bacteria-laden cells, could contribute to a non-linear relationship between inoculum size and the number of viable bacteria recovered. The invasiveness of strains assayed in quantitative RIIA (or in cell monolayers) is determined by the ratio - viable gentamicin-resistant bacteria recovered from homogenised ileal mucosa: initial inoculum. This practice is commonly used because accurate prediction of viable count of inoculum cannot be made before the experiment. The validity of this measurement depends on the linearity of the dose-response relationship between the challenge inoculum and the numbers of bacteria recovered in tissue homogenates. Dose-response experiments were performed with Typhimurium strain TML, Choleraesuis strain A50 and Dublin strain 3246 with individual rabbits used for each serotype. Inocula were prepared to cover the normal range used in these experiments. All three strains exhibited a linear (Typhimurium strain TML, Choleraesuis strain A50) or near linear (Dublin strain 3246) relationship between inoculum size and viable bacteria recovered (Fig. 1). Therefore, it was concluded that invasion data could be plotted as the ratio - 'numbers of viable bacteria recovered: initial inoculum' expressed as a percentage. The deviation of invasiveness of Dublin strain 3246 from linearity above inocula of $c .5 \times 10^{8}$ was interpreted to reflect the tissue-damaging effect of that strain.

\section{RIIAs with Typhimurium strains}

Typhimurium strains GM1-10 were tested in RIIAs and Typhimurium strains TML and LT7 were used as positive and negative controls, respectively. Each strain was tested first in ileal mucosa from two rabbits; the 


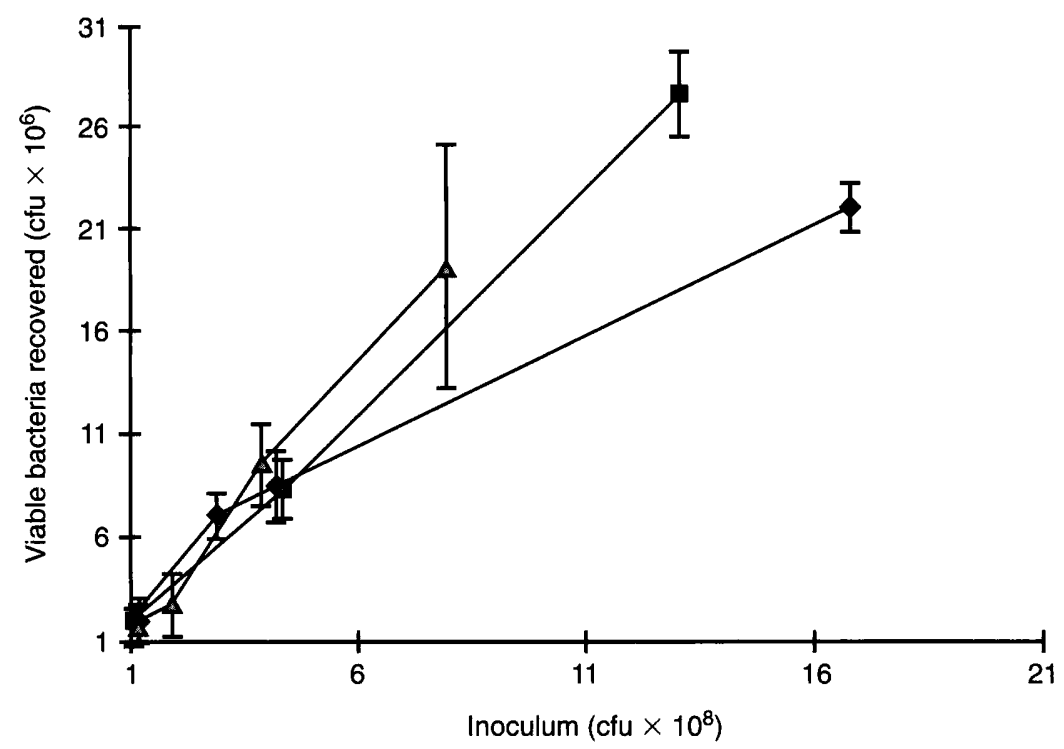

Fig. 1. Dose-response relationship between inoculum size and number of viable organisms recovered from RIIAs for three Salmonella serotypes: Typhimurium strain TML $(\Delta)$, Choleraesuis strain A50 ( $\square$ ) and Dublin strain $3246(\diamond)$. Ileal tissue from a different rabbit was used for each serotype. A linear relationship was obtained for Typhimurium strain TML and Choleraesuis strain A50, justifying the measurement of invasiveness as the ratio 'percentage organisms recovered/organisms in inoculum'. For Dublin strain 3246 there was a departure from linearity above inocula of $c$. $5 \times 10^{8}$. Each point is the mean recovery from three chambers. Error bars: SEM.

bacterial recovery data indicated a spectrum of invasiveness with a near normal distribution of invasiveness of these strains about the value for strain TML (Fig. 2). It is obvious that more experiments would be required to assign with statistical precision the relative invasiveness of each strain, particularly those represented by strains GM1, GM2 and GM7; however, this was not logistically possible. Strain GM3, which exhibited the lowest, and strain GM7, which (with strain GM1) exhibited the highest degrees of invasiveness were subsequently re-tested with ileal mucosa from a further four and two rabbits, respectively; these data are combined (Fig. 2).

As one of the objectives of this work was to establish a broader base upon which to rest the assertion that intestinal invasiveness is a prerequisite for Typhimurium enteropathogenicity, strain GM3, the least invasive of the Typhimurium strains, was examined further. Preparations of strain GM3 from a glycerol stock, and

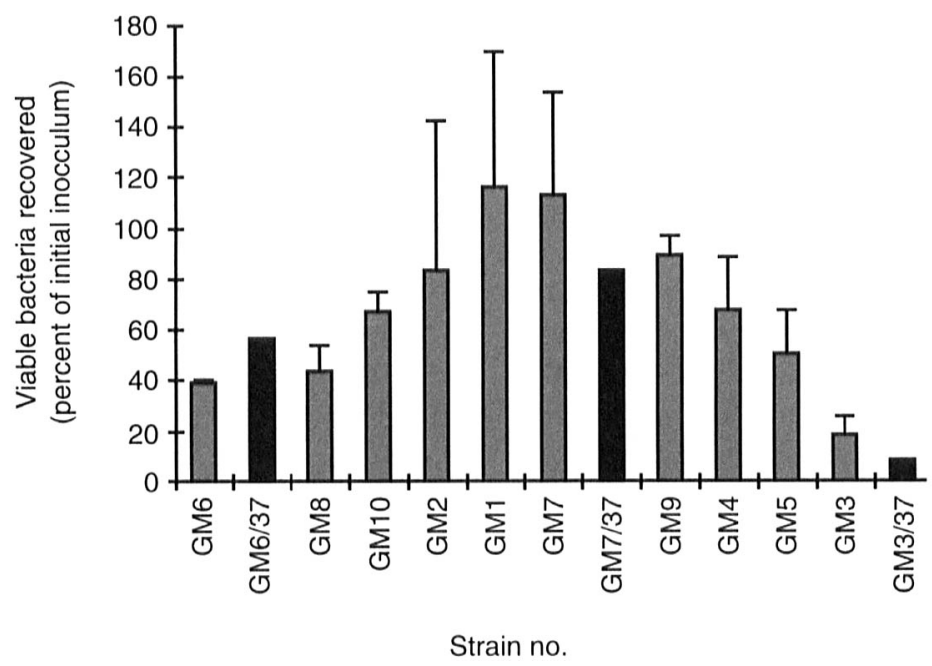

Fig. 2. Recovery of Typhimurium strains GM1-10 from RIIAs, with organisms grown at $37^{\circ} \mathrm{C}$ and stored at $4^{\circ} \mathrm{C}$, or grown and used fresh at $37^{\circ} \mathrm{C}$. For organisms grown at $37^{\circ} \mathrm{C}$ and stored at $4{ }^{\circ} \mathrm{C} \mathrm{(G)}$ a minimum of two experiments was performed with each strain; however, for strains GM3 and GM7, six and four experiments were performed respectively. Data are normalised to that for strain TML used as positive control with tissue from the same rabbit as that used for the test strain. Each column represents the mean and SEM of each set of experiments in which the invasiveness of different strains was compared to that of strain TML. For strains GM3, GM6 and GM7, one experiment was performed with each strain grown at $37^{\circ} \mathrm{C}(\mathrm{GM} 3 / 37, \mathrm{GM} 6 / 37$ and $\mathrm{GM} 7 / 37(\boldsymbol{\square}))$ and used fresh without previous storage at $4^{\circ} \mathrm{C}$ and the results were compared to those for strain TML similarly treated. 
directly from Dorset's egg storage slopes were compared. The invasiveness of the two preparations was not different. Furthermore, the invasiveness of strain GM3 in four separate inocula, each derived from randomly selected single colonies, was not different from that of inocula prepared from colony sweeps or from each other (data not shown).

The effect of temperature on the three Typhimurium strains - GM3, GM6 and GM7 - in RIIAs was assessed. In one experiment, the invasiveness of strain GM3 (low), strain GM6 (intermediate) and GM7 (high invasiveness) was assessed with freshly prepared suspensions; no major temperature-mediated differences in the levels or patterns of invasiveness for these strains were observed (Fig. 2).

\section{RIIAs with salmonellae of host-restricted serotypes}

After storage at $4^{\circ} \mathrm{C}$, the invasiveness for rabbit ileum of Choleraesuis strain A50 and of Dublin strain 3246 was similar to each other and to that of Typhimurium strain TML (Fig. 3a). In experiments 1, 3 and 4 there was considerable chamber variation for Dublin strain 3246 stored at $4^{\circ} \mathrm{C}$; this observation was explained in terms of irregular cell shedding damage seen in some villi (Fig. 4e). However, the degree of damage was as nothing compared with the extensive damage caused by strain 3246 grown at $37^{\circ} \mathrm{C}$ and used fresh (Fig. 4d), as reflected in the very low numbers of organisms recovered (Fig. 3b). In contrast, the invasiveness of Typhimurium strain TML and Choleraesuis strain A50 were not affected by temperature (Fig. 3b).

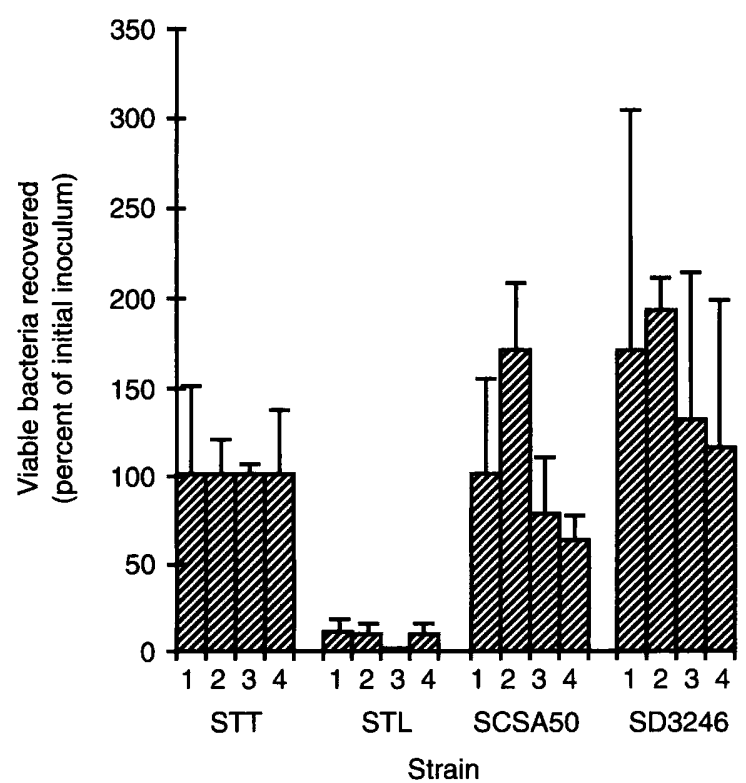

\section{Electron microscopy}

Electron microscopy of ileal mucosae, after interaction with Dublin strain 3246, Choleraesuis strain A50 and Typhimurium strains GM3 and GM7, showed clear evidence that freshly grown Dublin strain 3246 caused considerable damage to the tissue (Fig. 4b, c, d, k, 1). In contrast, much less gross damage was seen in mucosa challenged with Dublin strain 3246 when it was used after storage at $4^{\circ} \mathrm{C}$ (Fig. $4 \mathrm{e}, \mathrm{h}, \mathrm{j}$ ).

After exposure to fresh suspensions of Dublin strain 3246 for $1 \mathrm{~h}$, enterocytes were seen to separate from each other and were shed from the surface of villi, especially in areas where the presence of bacteria was demonstrated with difficulty (Fig. 4b). Extruded enterocytes were deformed, had lost their brush border and had become balloon-like (Fig. 4c). After exposure to Dublin strain 3246 for $3 \mathrm{~h}$, epithelia were disintegrated (Fig. 4l) and villi became overlaid with 'collapsed' enterocytes after they had been shed (Fig. 4d). A similar picture was observed with Typhimurium strain GM3 when it was used fresh or after storage at $4^{\circ} \mathrm{C}$. As strain GM3 is the subject of a detailed study [3], only the initial tight junction-cleaving effect is shown here (Fig. $4 \mathrm{~m}$ ); it is remarkably similar to that caused by Dublin strain 3246 (Fig. 4k). In contrast, even after incubation for $3 \mathrm{~h}$, Dublin strain 3246, grown at $37^{\circ} \mathrm{C}$ and stored at $4^{\circ} \mathrm{C}$, was observed entering enterocytes by brush borders (Fig. $4 \mathrm{~h}$ ) without cleavage of adjacent tight junctions (Fig. 4j) and caused only minor overall damage to villous architecture (Fig. 4e).

Little or no gross damage was seen when either

b

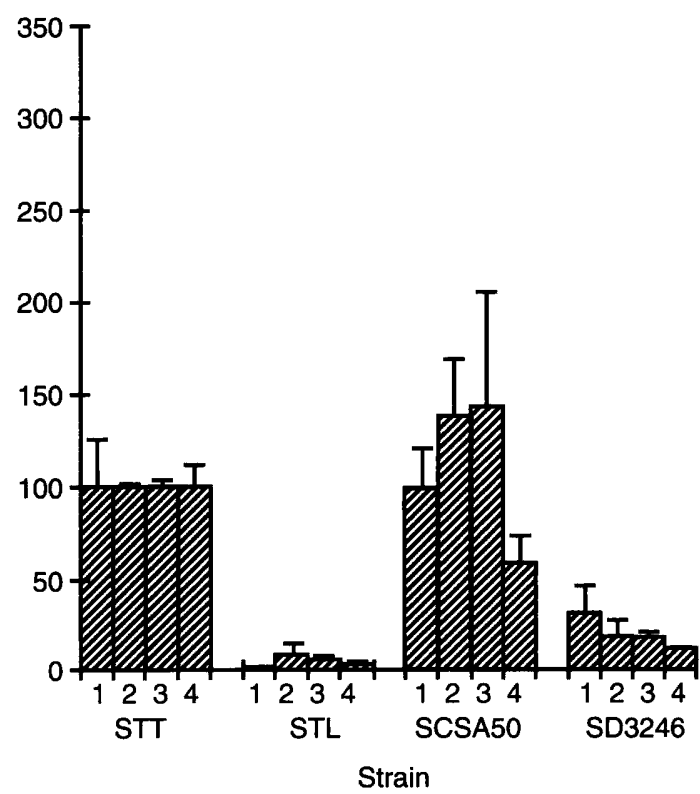

Fig. 3. Recoveries of Typhimurium strains TML (STT) and LT7 (STL), Choleraesuis strain A50 (SCSA50) and Dublin strain 3246 (SD3246) from RIIAs, with (a) organisms stored at $4^{\circ} \mathrm{C}$, (b) organisms freshly prepared at $37^{\circ} \mathrm{C}$. Data were normalised to those of STT. Each column represents the mean and SEM of three chambers. The numbers relate to individual experiments each of which was performed with tissue from one individual rabbit. 

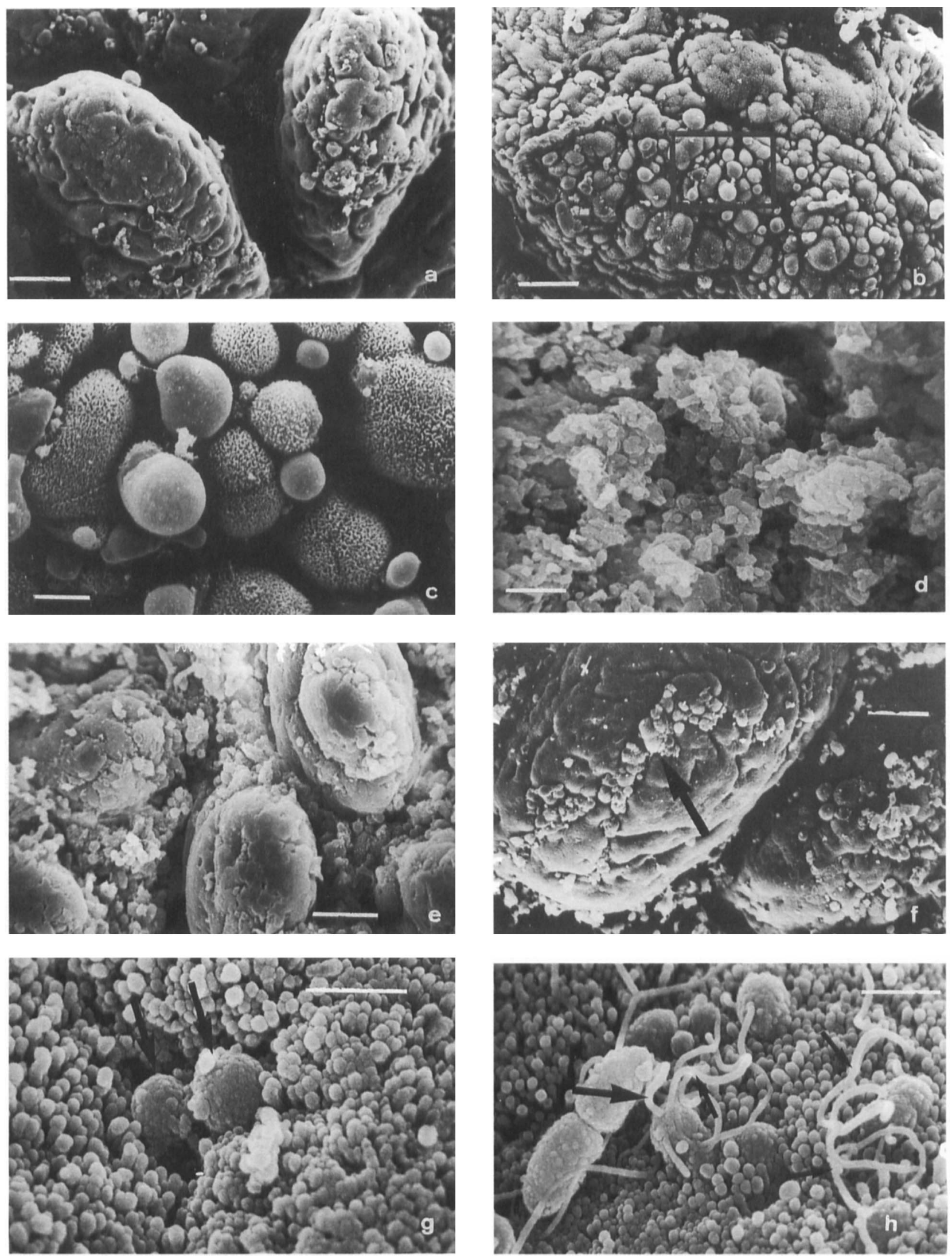

Fig. 4. Electron microscopy of tissues exposed to Dublin strain 3246, Choleraesuis strain A50 and Typhimurium strains GM3 and GM7. Scanning electron micrographs. (a) Control rabbit ileum showing well preserved villi; bar $=40 \mu \mathrm{m}$. (b) Villus $1 \mathrm{~h}$ after exposure to Dublin strain 3246 grown at $37^{\circ} \mathrm{C}$ and used fresh. Note the separation and shedding of enterocytes; bar $=30 \mu \mathrm{m}$. (c) Marked area in (b) showing extrusion of deformed balloon-like enterocytes which have lost their brush border; bar $=5 \mu \mathrm{m}$. (d) Villi $3 \mathrm{~h}$ after exposure to Dublin strain 3246 grown at $37^{\circ} \mathrm{C}$ and used fresh. Note the extensive overlying of cellular debris comprising mainly 'collapsed' enterocytes. An almost identical picture was observed with Typhimurium strain GM3 (not shown); bar $=40 \mu \mathrm{m}$. (e) Villi after exposure for $2 \mathrm{~h}$ to Dublin strain 

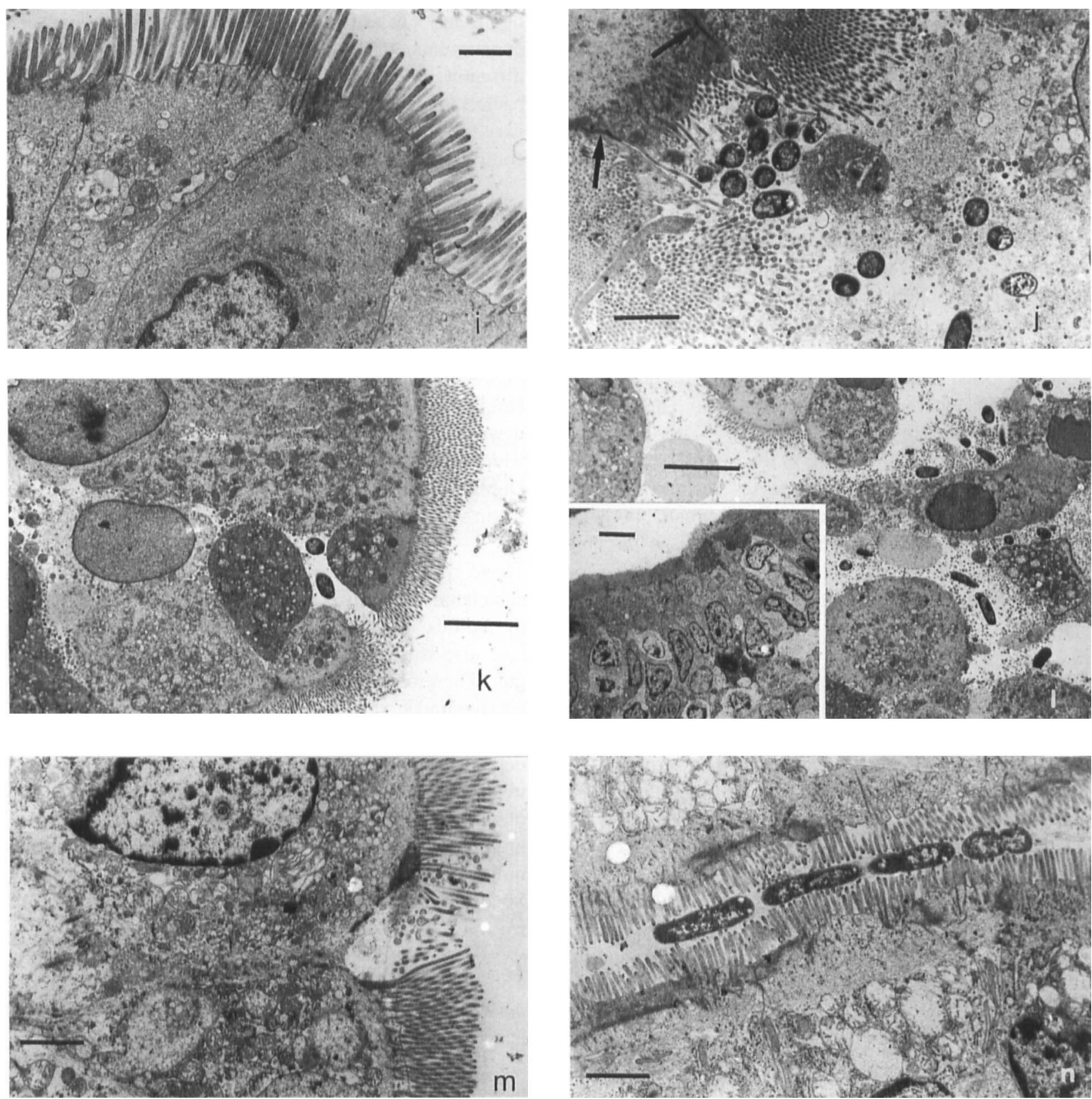

3246 grown at $37^{\circ} \mathrm{C}$ and stored at $4{ }^{\circ} \mathrm{C}$ overnight before use. Note the huge difference between this picture - in which villi are largely intact with only a small amount of overlying cellular debris - and (d); bar $=40 \mu \mathrm{m}$. (f) Villi after exposure for $3 \mathrm{~h}$ to Choleraesuis strain $\mathrm{A} 50$ grown at $37^{\circ} \mathrm{C}$ and used fresh. Note intact villi showing zones of accelerated cell shedding (arrow) very similar to that seen with Typhimurium strain TML [5]; bar $=40 \mu \mathrm{m}$. (g) Typhimurium strain TML organisms (grown at $37^{\circ} \mathrm{C}$ and used fresh; arrows) penetrating brush borders with little or no disturbance to adjacent microvilli in a manner identical to that described earlier [6]. Choleraesuis strain A50 (grown at $37^{\circ} \mathrm{C}$ and used fresh) similarly penetrated brush borders with minimal disruption; bar $=1 \mu \mathrm{m}$. (h) Dublin strain 3246 grown at $37^{\circ} \mathrm{C}$ and stored at $4^{\circ} \mathrm{C}$, penetrating brush border with little or no disturbance to adjacent microvilli. Note the appendages (arrows) which apparently become detached at entry; bar $=1 \mu \mathrm{m}$. Transmission electron micrographs. (i) Enterocytes from control villi after incubation in the organ-culture apparatus, showing good preservation and intact tight junctions; bar $=1 \mu \mathrm{m}$. (j) Dublin strain 3246 (grown at $37^{\circ} \mathrm{C}$ and stored at $4^{\circ} \mathrm{C}$ ), after incubation for $3 \mathrm{~h}$ penetrating enterocytes through brush border without cleaving the tight junctions (arrows) which remain intact; bar $=2 \mu \mathrm{m}$. (k) Ileal tissue after exposure for $3 \mathrm{~h}$ to Dublin strain 3246 (grown at $37^{\circ} \mathrm{C}$ and used fresh). This field shows initial cleavage of tight junctions and detachment of a cell which still has a full complement of microvilli and the presence of organisms in the intercellular space; bar $=4 \mu \mathrm{m}$. (l) This field shows the progressive destruction of epithelia $3 \mathrm{~h}$ after exposure to Dublin strain 3246 (grown at $37^{\circ} \mathrm{C}$ and used fresh); bar $=5 \mu \mathrm{m}$. Note in both (k) and (l) that organisms between adjacent cells and among detached cell debris would not be protected from gentamicin. Inset in (l) shows a typical villus epithelium, which remains largely intact after exposure for $3 \mathrm{~h}$ to Choleraesuis strain A50; bar $=10 \mu \mathrm{m}$. (m) Typhimurium strain GM3 induced damage very similar to that caused by Dublin strain 3246; only initial cleavage of tight junctions shown; bar $=1.5 \mu \mathrm{m}$. (n) Note the intact brush borders of enterocytes despite the high density of Typhimurium strain GM7 organisms; bar $=4 \mu \mathrm{m}$. This strain is clearly not as tissue destructive as Dublin strain 3246 and Typhimurium strain GM3. In other fields (not shown) organisms were observed penetrating brush borders. 
Choleraesuis strain A50 (Fig. 4f 41 inset) or Typhimurium strain TML was used fresh without storage at $4^{\circ} \mathrm{C}$; they entered enterocytes by brush borders (Fig. 4g) with none of the features associated with entry of Dublin strain 3246 (see Fig. 4b, c). Freshly grown Typhimurium strain GM7 was not tested for histotoxicity, because no difference in temperature-modulated invasiveness had been observed. Indeed, Fig. $4 \mathrm{n}$ shows a field where Typhimurium strain GM7 was seen in high density next to enterocytes with intact brush borders; in other fields, bacteria were observed entering cells by the brush borders (not shown).

When mucosal damage occurred, it was not confined to those areas where bacteria were seen. The overall picture was one of rapid cleavage of tight junctions between enterocytes, resulting in the loss of enterocytes into the lumen. Detached enterocytes became balloonlike and lost their differentiated brush borders. Epithelia were thereby disrupted allowing the possibility of tissue invasion to occur by routes other than, or in addition to, enterocyte apical membranes.

\section{Discussion}

Several points from this work bear upon the significance of the invasiveness of Salmonella in terms of the nature of the interaction of invasive enteropathogens and the gut, and the assessment of invasiveness in 'gentamicin-protection assays'.

Although Typhimurium strain GM3 superficially appeared to be a relatively non-invasive strain, it caused considerable damage to ileal mucosa. This finding explained the relatively low recoveries of gentamicinresistant bacteria in these assays: cells were either damaged, allowing gentamicin to penetrate and kill intracellular organisms, or were dislodged and hence not part of the final tissue homogenate, or both. The difference in the abilities of Typhimurium strains GM3 and GM7 to damage ileal epithelia was considerable.

Dublin strain 3246 also caused much damage to ileal mucosa, but only when it was used freshly grown at $37^{\circ} \mathrm{C}$. The temperature-mediated differences were almost certainly not due to lower initial numbers of organisms invading the tissue; the invasiveness of Typhimurium strain TML and Choleraesuis strain A50 was not temperature-dependent. This observation contrasts with the earlier report that, in absolute terms, bacteria stored at $4^{\circ} \mathrm{C}$ exhibited lower levels of invasiveness than freshly grown bacteria, whilst exhibiting similar patterns of relative invasiveness [7]. A satisfactory explanation for this apparent discrepancy is not possible, but two explanations can be proposed. First, between-animal variations in susceptibility of gut to invasion are likely [2]. Second, the conditions for optimal induction and maintenance of the bacterial invasive phenotype in these short-term invasion experi- ments are not yet defined. Thus, differences between experiments, or batches of experiments performed at different times with different groups of animals and bacteria inocula, might be expected. What does not vary is the pattern of invasiveness with respect to control standard strains.

Expression of a putative mucosa-damaging toxin is apparently modulated by temperature in Dublin strain 3246, but not in Typhimurium strain GM3. The phenomenon of temperature regulation of virulence genes is well documented in Shigella and Yersinia $[8,9]$; the data presented in this study might imply the existence of such a toxin in one strain of Salmonella Dublin but this was not investigated in detail. However, it was possible to demonstrate that under conditions in which toxin was not expressed, the invasiveness of Dublin strain 3246 was similar to that of Choleraesuis strain A50.

These results suggest that enteropathogenicity can be correlated with initial invasiveness for gut epithelia: all the strains tested, including Typhimurium strain GM3 (see also ref. [3]), were invasive for explants of rabbit gut. Therefore, it is highly likely that many virulent enteropathogenic Typhimurium strains are invasive. Nevertheless, it is clear that subgroups with different degrees of invasiveness existed. The question arises as to whether such degrees of invasiveness reflect degrees of virulence, or whether there is a minimum degree of invasiveness that is sufficient to trigger the subsequent biological sequelae that give rise to clinical disease. Such a detailed analysis was beyond the scope of this work.

The demonstration that enteropathogenicity of Salmonella serotype Typhimurium correlates with invasiveness poses the interesting, but as yet unresolved, challenge [10] of interpreting the pathophysiological basis of Typhimurium-induced diarrhoeal disease. Precisely what constitutes the post-invasive cascade of events or the biochemical determinants that give rise to diarrhoeal fluid secretion caused by Typhimurium is still unclear. Previous studies with Typhimurium strains of human origin showed a direct correlation between invasiveness and ability to induce an influx of polymorphonuclear cells (PMNLs), and the ability to induce fluid secretion in the rabbit [11]. However, induction of a PMNL response itself was insufficient to induce a fluid response. The phenotype of the organism, then undefined, except in terms of cultural characteristics, was also known to be important [11]. More recent studies with Dublin strain 2229 in calves (and HeLa cells) suggest that a secreted protein (SopB) is translocated via the Sip system into epithelial cells and plays a significant, although partial, role in the recruitment of PMNLs and induction of fluid secretion in calves [12]. However, the nature of the host response(s) stimulated by this or any other microbial effector which gives rise to the reversal of net 
absorption to hypersecretion is controversial, as exemplified in recent studies [13, 14].

From this study, three points arise regarding the route of invasion by Typhimurium. The first concerns the role of $\mathrm{M}$ cells. The concept that invasion of absorptive epithelial cells by salmonellae depends on the primary invasion of $\mathrm{M}$ cells has acquired almost canonical status based on observations made in mice $[15,16]$. However, it has been shown in bovine ligated ileal loops, that $3 \mathrm{~h}$ after challenge no difference in the numbers of Typhimurium or Dublin recovered from ileal mucosa with or without Peyer's patches was noted [17]. A later study by the same group showed that initial interaction between Typhimurium and $M$ cells occurred earlier than with absorptive enterocytes [18]. The present study showed that, in the rabbit model, invasion of enterocytes does not depend on primary invasion of $M$ cells. Again, it is now clear that invasiveness of the gut in vivo by histotoxic strains of Typhimurium is exceedingly difficult to define. As shown here, salmonellae that are histotoxic for gut epithelia alter the nature of the tissue being invaded. Tight junctions are opened up and bacteria are found in the intercellular spaces with new cells and surfaces to be negotiated and where organisms might be susceptible to gentamicin. The importance of careful histological analysis in the interpretation of invasion/survival assays of Salmonella has been emphasised recently in relation to studies with MDCK cells, Int 407 cells and bovine ileum in vivo [17] and with macrophages [19]. The work described here reinforces the fact that detailed interpretation of quantitative data from bacterial invasion assays - particularly when using multicellular differentiated tissues such as gut can best be obtained when accompanied by histological analysis. When dealing with toxin-producing strains of Salmonella, it is certain that experimental estimates of invasiveness in vitro are underestimated. A corollary to these findings is that the importance of the intracellular habitat in vivo for pathogens such as cytotoxinproducing Salmonella may be overestimated. The opening of tight junctions described in these experiments does not depend on the extrusion of PMNLs, as suggested for Shigella [20].

Evidence that the host-restricted serotypes Choleraesuis and Dublin showed differences in their ability to invade rabbit gut in vitro, under conditions in which the tissuedamaging effects of Dublin were suppressed was not obtained. The hypothesis that host restriction is determined by the relative ease with which these serotypes invade their respective susceptible hosts awaits comparative studies on porcine and bovine tissues.

The results of the present study suggest that, in the context of gut invasion, there are at least two different types of Salmonella, that cross serotypic boundaries one causes rapid initial histotoxic damage to mucosal epithelia and the other does not. This work also implies that there may be a gut-damaging toxin produced by some Salmonella strains that opens up several cellular routes for invasion of the gut by virtue of early damage to gut enterocytes and exposure of subepithelial cells and tissues. This question has been addressed for Typhimurium strain GM3 in another study [3], which provides formal proof that the histotoxic activity of this strain is in fact toxinmediated.

We thank BBSRC for grant supporting for A.J.B. and a studentship for G.D.M., Dr B. Rowe for strains of the gift of Salmonella and Paul Stanley and Trevor Hayward for assistance with electron microscopy and photography.

\section{References}

1. Stephen J, Wallis TS, Starkey WG, Candy DCA, Osborne MP, Haddon S. Salmonellosis: in retrospect and prospect. In: Evered D, Whelan J (eds) Microbial toxins and diarrhoeal disease (Ciba Foundation Symposium 112). London, Pitman. 1985: 175-188.

2. Amin II, Douce GR, Osborne MP, Stephen J. Quantitative studies of invasion of rabbit ileal mucosa by Salmonella typhimurium strains which differ in virulence in a model of gastroenteritis. Infect Immun 1994; 62: 569-578.

3. Lodge J, Bolton AJ, Martin GD, Osborne MP, Ketley JM, Stephen J. A histotoxin produced by Salmonella. J Med Microbiol 1999; 48: 811-818.

4. De Kort G, Bolton A, Martin G, Stephen J, Van de Klundert JAM. Invasion of rabbit ileal tissue by Enterobacter cloacae varies with the concentration of OmpX in the outer membrane. Infect Immun 1994; 62: 4722-4726.

5. Wallis TS, Starkey WG, Stephen J, Haddon SJ, Osborne MP, Candy DCA. The nature and role of mucosal damage in relation to Salmonella typhimurium-induced fluid secretion in the rabbit ileum. $J$ Med Microbiol 1986; 22: 39-49.

6. Worton KJ, Candy DCA, Wallis TS et al. Studies on early association of Salmonella typhimurium with intestinal mucosa in vivo and in vitro: relationship to virulence. $J$ Med Microbiol 1989; 29: 283-294.

7. Lodge J, Douce GR, Amin II et al. Biological and genetic characterization of TnphoA mutants of Salmonella typhimurium TML in the context of gastroenteritis. Infect Immun 1995; 63: $762-769$.

8. Hromockyj AE, Tucker SC, Maurelli AT. Temperature regulation of Shigella virulence: identification of the repressor gene $v i r R$, an analogue of $h n s$, and partial complementation by tyrosyl transfer RNA (tRNA1Tyr). Mol Microbiol 1992; 6: 2113-2124.

9. Pepe JC, Badger JL, Miller VL. Growth phase and low pH affect the thermal regulation of the Yersinia enterocolitica inv gene. Mol Microbiol 1994; 11: 123-135.

10. Stephen J, Amin II, Douce GR. Experimental Salmonella typhimurium-induced gastroenteritis. In: Cabello F, Hormaeche C, Mastroeni P, Bonina L (eds) Biology of Salmonella. (NATO ASI Series A vol. 245.) New York, Plenum Press. 1993: 199-209.

11. Wallis TS, Hawker RJH, Candy DCA et al. Quantification of the leucocyte influx into rabbit ileal loops induced by strains of Salmonella typhimurium of different virulence. $J \mathrm{Med}$ Microbiol 1989; 30: 149-156.

12. Galyov EE, Wood MW, Rosqvist R et al. A secreted effector protein of Salmonella dublin is translocated into eukaryotic cells and mediates inflammation and fluid secretion in infected ileal mucosa. Mol Microbiol 1997; 25: 903-912.

13. Eckmann L, Stenson WF, Savidge TC et al. Role of intestinal epithelial cells in the host secretory response to infection by invasive bacteria. Bacterial entry induces epithelial prostaglandin $\mathrm{H}$ synthase-2 expression and prostaglandin E-2 and F-2 alpha production. $J$ Clin Invest 1997; 100: 296-309.

14. Jensen GM, Grondahl ML, Nielsen CG, Skadhauge E, Olsen JE, Hansen MB. Effect of ondansetron on Salmonella typhimurium-induced net fluid accumulation in the pig jejunum 
in vivo. Comp Biochem Physiol A 1997; 118: 297-299.

15. Jones $\mathrm{BD}$, Ghori N, Falkow S. Salmonella typhimurium initiates murine infection by penetrating and destroying the specialized epithelial M cells of the Peyer's Patches. J Exp Med 1994; 180: 15-23.

16. Penheiter KL, Mathur N, Giles D, Fahlen T, Jones BD. Noninvasive Salmonella typhimurium mutants are avirulent because of an inability to enter and destroy $M$ cells of ileal Peyer's patches. Mol Microbiol 1997; 24: 697-709.

17. Watson PR, Paulin SM, Bland AP, Jones PW, Wallis TS. Characterization of intestinal invasion by Salmonella typhimurium and Salmonella dublin and effect of a mutation in the
invH gene. Infect Immun 1995; 63: 2743-2754.

18. Frost AJ, Bland AP, Wallis TS. The early dynamic response of the calf ileal epithelium to Salmonella typhimurium. Vet Pathol 1997; 34: 369-386.

19. Guilloteau LA, Wallis TS, Gautier AV, Macintyre S, Platt DJ, Lax AJ. The salmonella virulence plasmid enhances salmonella-induced lysis of macrophages and influences inflammatory responses. Infect Immun 1996; 64: 3385-3393.

20. Parsot C, Sansonetti PJ. Invasion and the pathogenesis of Shigella infections. In: Miller VI (ed) Bacterial invasiveness. (Current topics in microbiology and immunology 209). Berlin, Springer. 1996: 25-42. 